\title{
Damage Characterisation of Thermally Shocked Cross-Ply Ceramic Composite Laminates
}

\author{
C. KASTRITSEAS, P. A. SMITH, J. A. YEOMANS* \\ School of Engineering (H6), University of Surrey, Guildford GU2 7XH, Surrey, UK \\ E-mail: j.yeomans@surrey.ac.uk
}

\begin{abstract}
Damage due to thermal shock in cross-ply Nicalon/calcium aluminosilicate ceramic matrix composites has been investigated. Heated specimens of two simple $\left[\left(0^{\circ} / 90^{\circ}\right)_{\mathrm{s}}\right.$ and $\left.\left(90^{\circ} / 0^{\circ}\right)_{\mathrm{s}}\right]$ and two multi-layer $\left[\left(0^{\circ} / 90^{\circ}\right)_{3 \mathrm{~s}}\right.$ and $\left.\left(90^{\circ} / 0^{\circ}\right)_{3 \mathrm{~s}}\right]$ materials were quenched into water at room temperature. Crack morphologies were assessed by reflected light microscopy and scanning electron microscopy. The use of image assembling software allowed the generation of reflected light microscopy images of all of the thermally-shocked surfaces onto which the crack patterns were then superimposed. This allowed clear identification of damage mechanisms and accurate quantification of damage accumulation with increasing severity of thermal shock. Damage was first detected in the central plies of each composite. Composites with $0^{\circ}$ central plies exhibited slightly higher resistance to thermal shock than their counterparts with $90^{\circ}$ central plies. Although damage extended to the outer plies as the severity of the shock increased, crack density was found to vary with position at every shock: it was highest in the central plies and gradually reduced towards the outer plies. Multiple matrix cracking perpendicular to the fibre direction was the damage mode identified in $0^{\circ}$ plies, while $90^{\circ}$ plies contained cracks that ran along the ply length. At more severe shocks the morphology of these crack patterns was affected in significantly different ways. In addition, the thinner, simple cross-ply
\end{abstract}

\footnotetext{
* Author to whom all correspondence should be addressed
} 
composites exhibited much higher resistance to thermal shock than their multilayer counterparts.

\section{Introduction}

As fibre-reinforced ceramic matrix composites (CMCs) are being considered increasingly for high-performance engines and other applications, it is becoming apparent that there is a need to understand better their behaviour under conditions of 'thermal shock'. This term describes an event in which a sudden (usually downward) temperature change generates stresses in the material that can lead to cracking and long-term property degradation [1]. Such events are common in high-temperature machinery, e.g. in the case of an emergency shut-down of a gas turbine.

Fibre-reinforced CMCs have been shown to exhibit better behaviour under conditions of thermal shock than their monolithic or particulate-reinforced counterparts [2]. With optimum selection of fibres and matrices, favourable residual stress conditions can be established in the matrix, which lead to increased resistance to crack initiation due to thermal shock. After cracks appear, the presence of crack-deflecting fibre-matrix interfaces ensures that the fibres remain largely unaffected, thus preserving the integrity of the material. However, damage due to thermal shock still has an adverse affect on mechanical and thermal properties. In addition, microstructural changes due to high temperature exposure have a detrimental effect on the performance of these materials under thermal shock conditions.

Recent studies have concentrated mostly on materials with continuous unidirectional (UD) fibres or on various types of porous 2-D $\mathrm{SiC} / \mathrm{SiC}$ prepared by chemical vapour infiltration. It was found that multiple matrix cracking perpendicular to the fibres was the main damage mode on the faces of UD CMCs that contained longitudinal fibres, accompanied by the appearance of 'thumb-nail' or 'thermal debond' matrix cracks on their end faces [3-10]. Large-scale porosity affected the behaviour of $2-\mathrm{D} \mathrm{SiC} / \mathrm{SiC}$, as the pores acted as crack initiation sites at shocks of moderate severity [11-13]. Information on the thermal shock behaviour of CMCs of other configurations has been limited [14, 15].

This paper presents comprehensive experimental data on the damage in cross-ply CMCs resulting from a thermal shock treatment. Four different configurations were investigated for 
shocks of increasing severity. The results presented include the determination of the onset of cracking, the identification of the modes of fracture, and damage quantification at each shock. The effect of the thickness of the material on its behaviour under thermal shock is also highlighted.

\section{Materials and Experimental Techniques}

Two plates of cross-ply CMC comprising Nicalon fibres in a calcium aluminosilicate (CAS) matrix were supplied by Rolls-Royce plc. The first was made by stacking together four plies of unidirectional material to create a composite with thickness $\sim 0.7 \mathrm{~mm}$ with a $\left(0^{\circ} / 90^{\circ}\right)_{\mathrm{s}}$ configuration. The second plate consisted of twelve plies of unidirectional Nicalon/CAS with a total thickness of $2.2 \mathrm{~mm}$ and a $\left(0^{\circ} / 90^{\circ}\right)_{3 \mathrm{~s}}$ configuration. In both plates the fibre volume fraction was 0.34 .

Both plates were cut using a water-cooled diamond saw into specimens with dimensions 6 $\mathrm{mm} \times 6 \mathrm{~mm} \times 0.7 \mathrm{~mm}\left(\left(0^{\circ} / 90^{\circ}\right)_{\mathrm{s}}\right)$ and $6 \mathrm{~mm} \times 6 \mathrm{~mm} \times 2.2 \mathrm{~mm}\left(\left(0^{\circ} / 90^{\circ}\right)_{3 \mathrm{~s}}\right)$. Longitudinal faces $\left(6 \mathrm{~mm} \times 0.7 \mathrm{~mm}\right.$ for the $\left(0^{\circ} / 90^{\circ}\right)_{\mathrm{s}}$ and $6 \mathrm{~mm} \times 2.2 \mathrm{~mm}$ for the $\left.\left(0^{\circ} / 90^{\circ}\right)_{3 \mathrm{~s}}\right)$ were ground using silicon carbide paper with grain size 320-400 grit and were subsequently polished using diamond paste to a $1 \mu \mathrm{m}$ finish. By preparing the longitudinal faces adjacent to these initial faces, the effect of thermal shock treatment could be assessed on four different configurations: simple $\left(0^{\circ} / 90^{\circ}\right)_{\mathrm{s}}$ and $\left(90^{\circ} / 0^{\circ}\right)_{\mathrm{s}}$ from the samples cut from the first plate and multi-layer $\left(0^{\circ} / 90^{\circ}\right)_{3 \mathrm{~s}}$ and $\left(90^{\circ} / 0^{\circ}\right)_{3 \mathrm{~s}}$ from the samples obtained from the second.

The water-quench test was employed to produce the thermal shock condition. Each specimen, after being heated for a short period of time in an electric muffle furnace at a pre-determined temperature, was dropped into a container with a large quantity (>10 1) of room-temperature $\left(\sim 20^{\circ} \mathrm{C}\right)$ water. It was then removed from the water bath and allowed to dry before microscopic examination.

The quenching temperature difference, $\Delta \mathrm{T}$, is defined as the difference between the temperature at which the material was held in the furnace and the temperature of the water bath. The critical quenching temperature difference, $\Delta \mathrm{T}_{\mathrm{c}}$, is the temperature differential that results in the onset of cracking. Temperature differentials in the range 100 to $800^{\circ} \mathrm{C}$ were investigated, with 2 or 3 specimens used at each $\Delta \mathrm{T}$. All specimens were initially held at high 
temperature for 15-20 minutes before quenching. It was found, however, that at the highest $\Delta \mathrm{Ts}$ investigated $\left(\Delta \mathrm{T}=700-800^{\circ} \mathrm{C}\right)$ this resulted in the formation of a thin glassy layer over the material surfaces, probably a by-product of oxidation processes, which obscured crack observation. To overcome this problem, specimens were held at the highest temperatures for shorter periods of time, i.e. 7-10 minutes.

Microscopic examination of the thermally-shocked specimens was carried out mainly using reflected light microscopy. Each surface under investigation was photographed section by section and the stored images were then assembled using suitable image assembling software to produce an image of the whole surface. The cracking pattern was imposed manually on the resulting image after careful observation of the real surface using microscopy. More detailed observation of crack patterns was also performed using a scanning electron microscope.

\section{Results}

\subsection{Simple Cross-Ply Nicalon/CAS Laminates}

\subsubsection{The $\left(0^{\circ} / 90^{\circ}\right)_{\mathrm{s}}$ Laminate}

The description of thermal shock damage on this laminate is given with reference to the nomenclature of Fig. 1. As can be seen, the central, thick transverse $\left(90^{\circ}\right)$ ply is designated as T1 (Transverse 1) while the adjacent longitudinal $\left(0^{\circ}\right)$ plies are designated as L1 (Longitudinal 1).
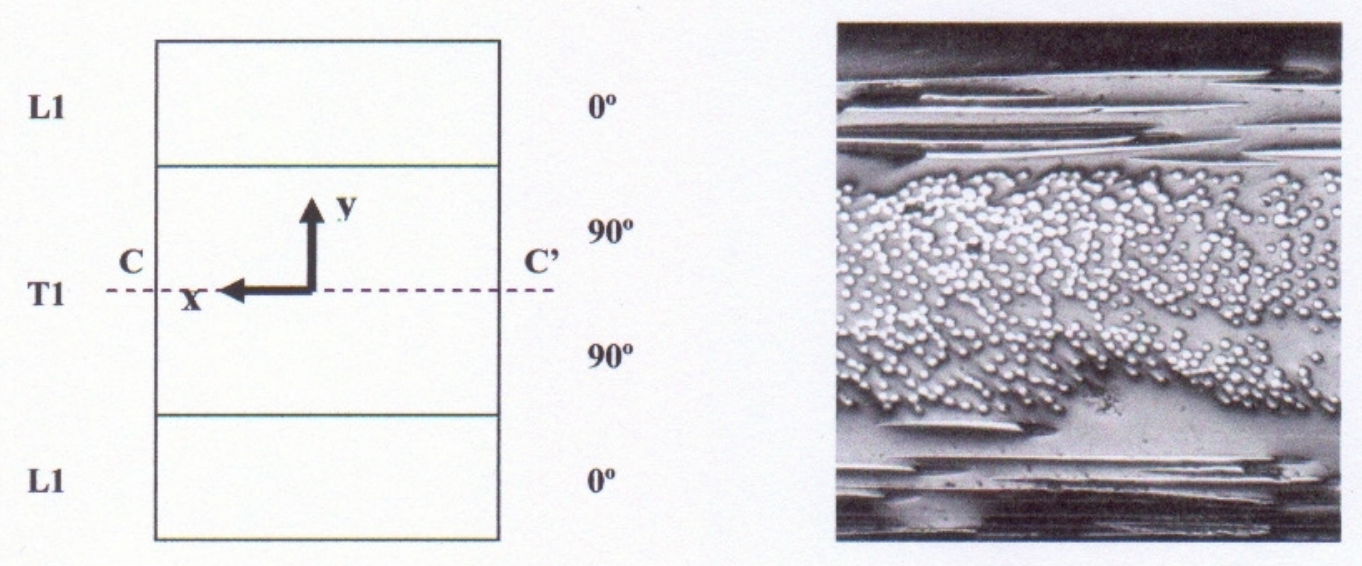

Figure 1 The nomenclature used to describe damage due to thermal shock on a $(0 / 90)_{\mathrm{s}}$ laminate

No damage was observed on the surfaces of material samples after quenching through temperature differentials lower than $450^{\circ} \mathrm{C}$, i.e. for $\Delta \mathrm{T}<450^{\circ} \mathrm{C}$. Some of the samples 
quenched through $\Delta \mathrm{T}=450^{\circ} \mathrm{C}$, the majority of the samples quenched through $\Delta \mathrm{T}=480^{\circ} \mathrm{C}$ and almost all of the samples tested through $\Delta \mathrm{T}=500^{\circ} \mathrm{C}$ showed evidence of cracking in the form of shallow, hair-like cracks. Thus, it was decided that the critical quenching temperature differential for this laminate lies in the range $450-500^{\circ} \mathrm{C}$, i.e. $\Delta \mathrm{T}_{\mathrm{c}}=450-500^{\circ} \mathrm{C}$. The actual value of $\Delta \mathrm{T}_{\mathrm{c}}$ seems to vary depending on experimental details, such as the angle of impact with the quenching medium, and the extent of pre-existing damage on the surfaces of the material. Generally, surfaces that exhibit at least some open porosity crack at $450^{\circ} \mathrm{C}$ or at temperature differentials close to this value.

The fracture mode identified on the surfaces of material samples shocked through $\Delta \mathrm{T} \geq 450^{\circ} \mathrm{C}$, was matrix cracking. If the direction of matrix cracks relative to the horizontal (i.e. the x-axis) is taken into account, matrix cracks can be further divided into those that run parallel and those that run perpendicular to the horizontal. These two types of cracking phenomena are termed 'Horizontal Matrix Cracks' (HMCs) and 'Perpendicular Matrix Cracks' (PMCs), respectively. It should be noted that no fibre breaks/failures could be observed even at the highest temperature differential investigated $\left(\Delta \mathrm{T}=700-800^{\circ} \mathrm{C}\right)$.

HMCs were the first form of damage seen after quenching through $\Delta \mathrm{T}=450-500^{\circ} \mathrm{C}$ (Fig. 2). They were located exclusively in the thick, central $90^{\circ}$ ply (T1) and each one was deflected at the successive fibre-matrix interfaces it encountered on its path. For this reason Graham et al. [10], who observed similar crack patterns on the transverse faces of UD Nicalon/lithium aluminosilicate (LAS) II after thermal shock, termed them 'thermal debond' cracks. HMCs seemed to appear randomly on the ply surface, although most of them could be seen towards the centreline (C-C') of the ply. 


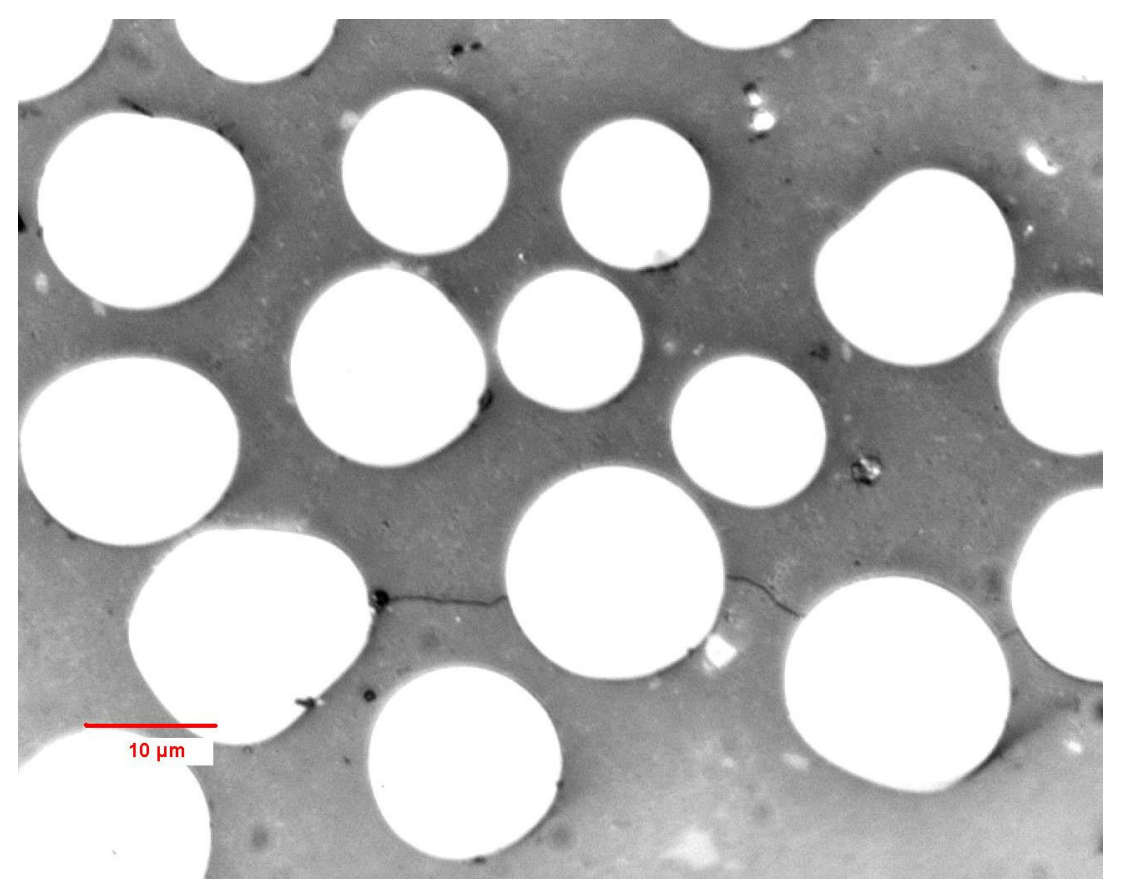

Figure 2 Photomicrograph of shallow, hair-like $\mathrm{HMC}$ on $\mathrm{T} 1$ at $\Delta \mathrm{T}=450^{\circ} \mathrm{C}$

PMCs were detected on the surfaces of thermally-shocked specimens of this laminate after quenching through $\Delta \mathrm{T}=500^{\circ} \mathrm{C}$, exclusively in the two $0^{\circ}$ plies (L1) adjacent to the thick, central $90^{\circ}$ ply. These cracks ran across the ply thickness, leaving the fibres on their path unaffected (Fig. 3).
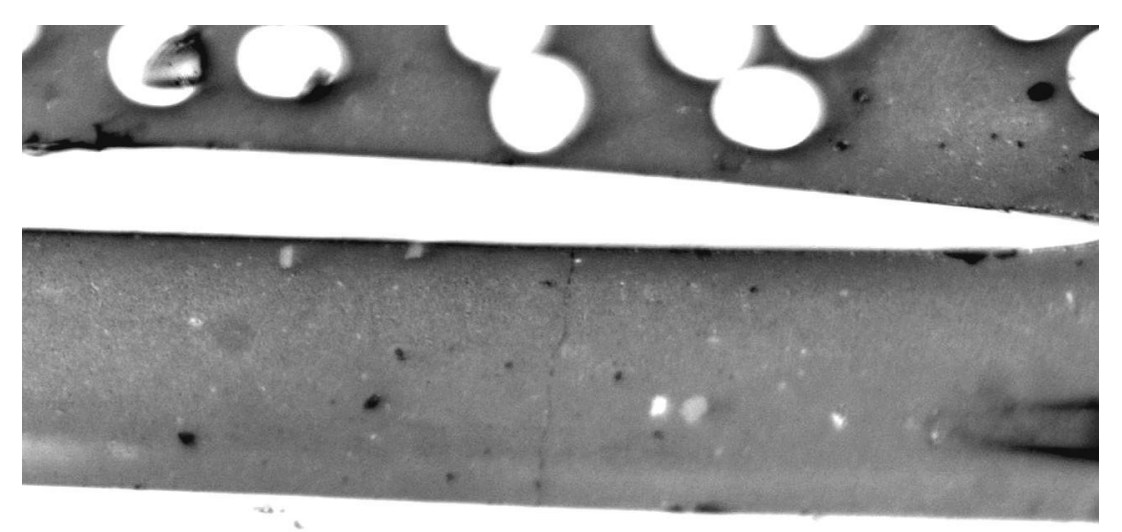

\section{$\overline{10 \mu \mathrm{m}}$}

Figure 3 Photomicrograph of $\mathrm{PMC}$ in $\mathrm{L} 1$ at $\Delta \mathrm{T}=500^{\circ} \mathrm{C}$ that arrests inside $0^{\circ}$ ply.

At $\Delta \mathrm{T}=450-500^{\circ} \mathrm{C}$, only a small number of HMCs were observed in $\mathrm{T} 1$. They did not penetrate deep into the matrix and had short lengths. The small number (1-2) of PMCs that were seen in $\mathrm{L} 1$ at $\Delta \mathrm{T}=500^{\circ} \mathrm{C}$ exhibited similar characteristics. In addition, they did not span the entire $0^{\circ}$ ply thickness but arrested at fibre-matrix interfaces inside the ply. 
At $\Delta \mathrm{T}=600^{\circ} \mathrm{C}$ a number of short, random HMCs were again observed in $\mathrm{T} 1$, while some PMCs in L1 could be seen to extend and bridge the whole $0^{\circ}$ ply thickness. Some HMCs seemed to connect and form 1-2 longer cracks in $\mathrm{T} 1$ at $\Delta \mathrm{T}=700^{\circ} \mathrm{C}$. At the same temperature differential, some PMCs not only bridged the $0^{\circ}$ ply thickness but also extended into the adjacent $90^{\circ}$ ply. Almost all PMCs, which had increased significantly in number, could be seen traversing the thickness of $\mathrm{L} 1$ at $\Delta \mathrm{T}=800^{\circ} \mathrm{C}$, while 1-2 longer $\mathrm{HMCs}$ ran along the length of T1.

The application of higher temperature differentials did not result in significant morphological changes in either HMCs or PMCs. Both damage mechanisms remained surface features of small depth. At all temperature differentials PMCs were evenly distributed between the two $0^{\circ}$ plies termed L1.

Crack densities for HMCs and PMCs were determined in terms of crack length per unit area $\left(\mathrm{mm} / \mathrm{mm}^{2}\right.$ or $\left.\mathrm{mm}^{-1}\right)$ in order to allow a comparison to be made, as shown in Figure 4. The failure of small, individual HMCs to connect at higher temperature differentials and form much longer cracks results in only a moderate increase in crack density with increasing applied shock. By contrast, the density of PMCs increases at a higher rate. Although PMCs appear at higher $\Delta \mathrm{T}$, they constitute the larger percentage of the total damage accumulated at the higher temperature differentials investigated.

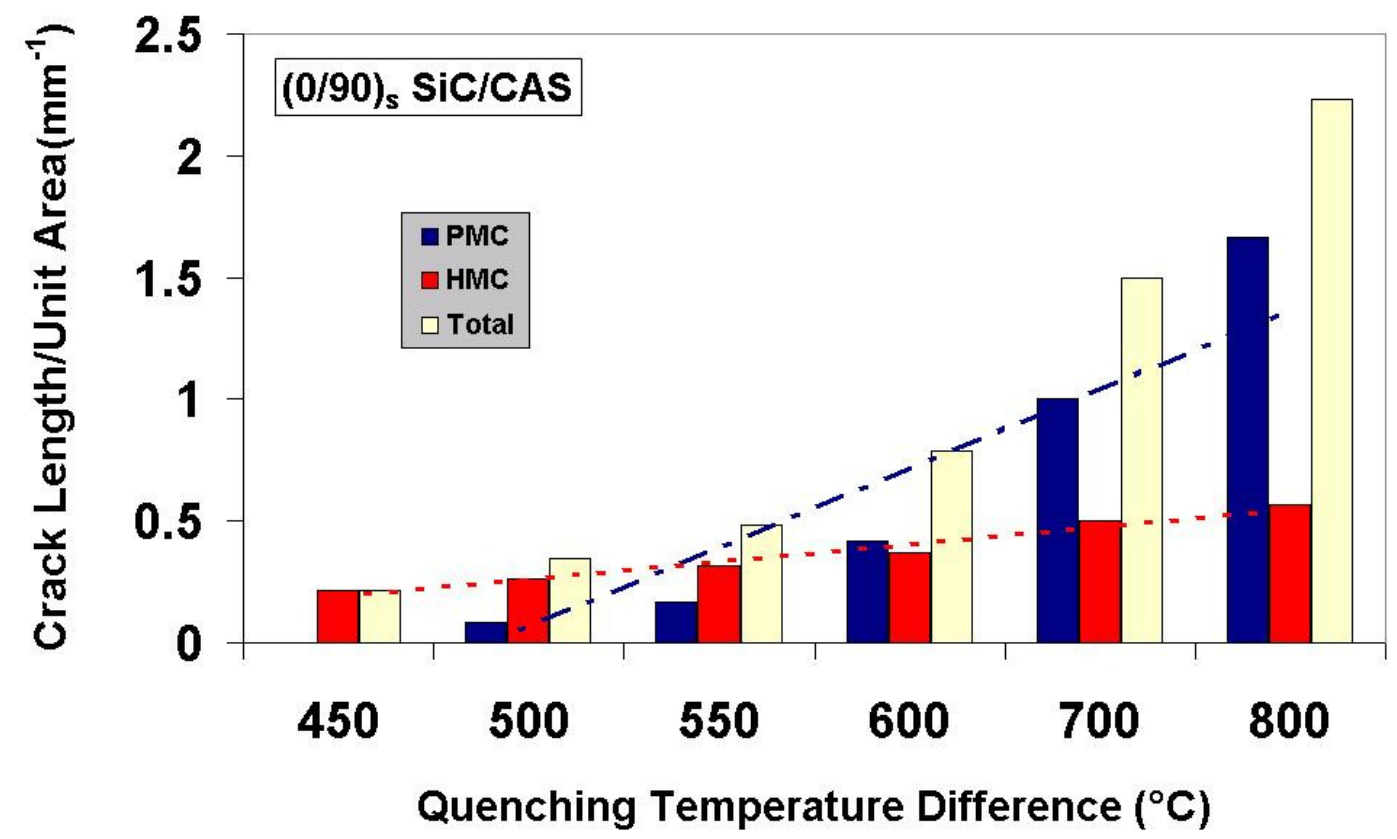

Figure 4 Crack densities of PMCs and HMCs and the total crack density at each $\Delta \mathrm{T}$. Relevant trends for each damage mode are also shown. 
Although an attempt was made to deduce different trends in crack density increase between successive quenching temperature differentials, the observed scatter in the measured crack density values did not allow for safe conclusions to be reached.

\subsubsection{The $\left(90^{\circ} / 0^{\circ}\right)_{\mathrm{s}}$ Laminate}

The description of this laminate is similar to that of the $\left(0^{\circ} / 90^{\circ}\right)_{\mathrm{s}}$ laminate except that the central, thick ply is in the $0^{\circ}$ configuration and designated L1, while the adjacent plies are in the $90^{\circ}$ configuration and designated as $\mathrm{T} 1$.

Damage due to thermal shock was observed using optical microscopy after quenching through temperature differentials higher than $500^{\circ} \mathrm{C}$. Thus, the critical quenching temperature differential for this laminate was determined to be $\Delta \mathrm{T}_{\mathrm{c}}=500^{\circ} \mathrm{C}$.

The main mode of damage due to thermal shock on this laminate was matrix cracking. Horizontal matrix cracks (HMCs) developed parallel to the $\mathrm{x}$-axis while perpendicular matrix cracks (PMCs) could be seen running at right angles to the $\mathrm{x}$-axis. No damage to the fibres could be detected even at the highest temperature differentials investigated.

PMCs were the first type of damage due to thermal shock to appear on the surfaces of this laminate. They were exclusively in the central, thick L1 ply at $\Delta \mathrm{T}=500^{\circ} \mathrm{C}$. They did not affect the longitudinal fibres on their path and were arrested at fibre-matrix interfaces inside the $0^{\circ}$ ply or at the interface between $0^{\circ}$ and $90^{\circ}$ plies.

HMCs or 'thermal debond' cracks appeared in the T1 plies of this laminate after quenching through $\Delta \mathrm{T}=550^{\circ} \mathrm{C}$. Only a few of these cracks could be observed and they were deflected at successive fibre-matrix interfaces. A major, long HMC could not be identified.

PMCs originating at $\Delta \mathrm{T}=500^{\circ} \mathrm{C}$ were few in number and did not penetrate deep inside the matrix material. In addition, they did not span the full thickness of the L1 plies. Most of the PMCs could be seen traversing the thickness of the central $\mathrm{L} 1$ ply at $\Delta \mathrm{T}=550^{\circ} \mathrm{C}$, while all of them bridged it at $\Delta \mathrm{T}=600^{\circ} \mathrm{C}$ before being arrested at the interface between $0^{\circ}$ and $90^{\circ}$ plies (Fig. 5). At the highest temperature differentials $\left(\Delta \mathrm{T}=700-800^{\circ} \mathrm{C}\right)$, some PMCs could be seen propagating a short distance inside the adjacent $90^{\circ}$ plies. 


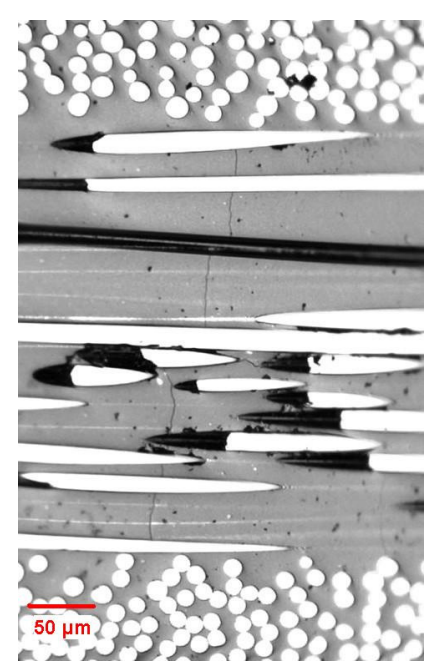

Figure $5 \mathrm{PMC}$ bridging L1 thickness at $\Delta \mathrm{T}=600^{\circ} \mathrm{C}$

A small number of short HMCs were almost evenly distributed between the T1 plies at all temperature differentials investigated. The increase in $\Delta \mathrm{T}$ resulted in a moderate increase in their length in most cases.

The depth and opening of both PMCs and HMCs was not altered by the application of higher temperature differentials. They both remained surface features throughout the temperature range investigated.

The number of PMCs increases significantly for higher $\Delta$ Ts while the crack density of HMCs shows only a moderate increase. The large difference in the rate of increase between the two types of matrix cracking is evident in the graph of Fig. 6. It can be seen that at all $\Delta \mathrm{Ts}$, about $2 / 3$ of the total thermal shock damage is due to the formation and extension of PMCs. 


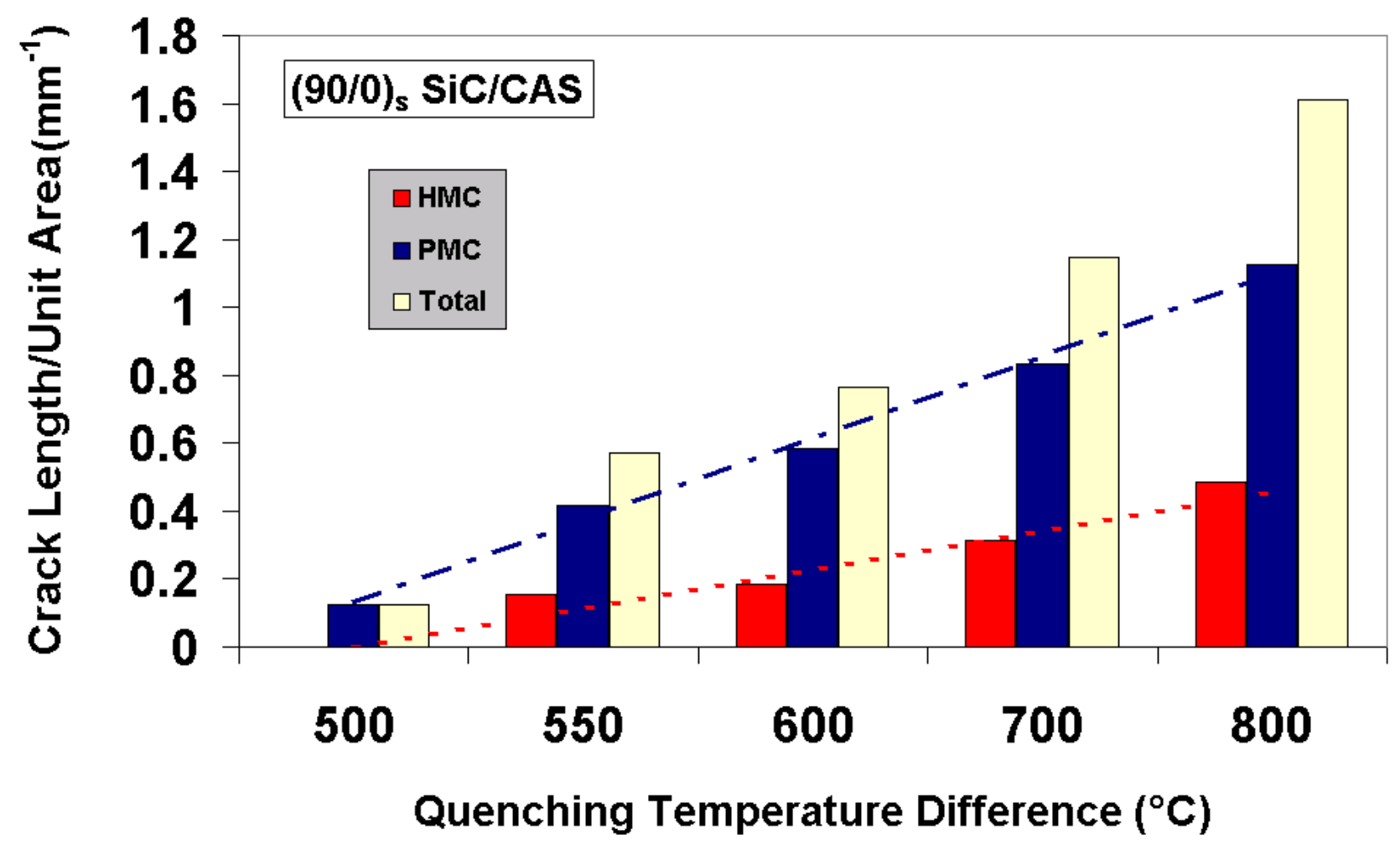

Figure 6 Crack densities of PMCs and HMCs and the total crack density at each $\Delta \mathrm{T}$. Relevant trends for each damage mode are also shown.

\subsubsection{Summary of Observations of Simple Cross-Ply Nicalon/CAS Laminates}

Damage due to thermal shock in simple cross-ply laminates was described and quantified in detail in this section. The main damage mechanism was found to be matrix cracking. Matrix cracks advanced parallel to the horizontal in transverse plies and at right angles to the horizontal in longitudinal plies. They were deflected at fibre-matrix interfaces at every quenching temperature investigated, so no fibre failures were observed.

The $\left(90^{\circ} / 0^{\circ}\right)_{\mathrm{s}}$ laminate exhibited better resistance to thermal shock than the $\left(0^{\circ} / 90^{\circ}\right)_{\mathrm{s}}$ laminate. However, damage in both laminates originated in the thick, central ply and then, at higher temperature differentials, extended to adjacent plies.

Matrix cracks in both laminates were found to remain shallow, surface features irrespective of the severity of thermal shock loading. However, damage in the form of PMCs was more extensive than damage in the form of HMCs in both laminates, especially at higher quenching temperature differences. 


\subsection{Multi-Layer Cross-Ply Nicalon/CAS Laminates}

\subsubsection{The $\left(0^{\circ} / 90^{\circ}\right)_{3 \mathrm{~s}}$ Laminate}

The description of thermal shock damage on this laminate is given with reference to the nomenclature of Fig. 7.
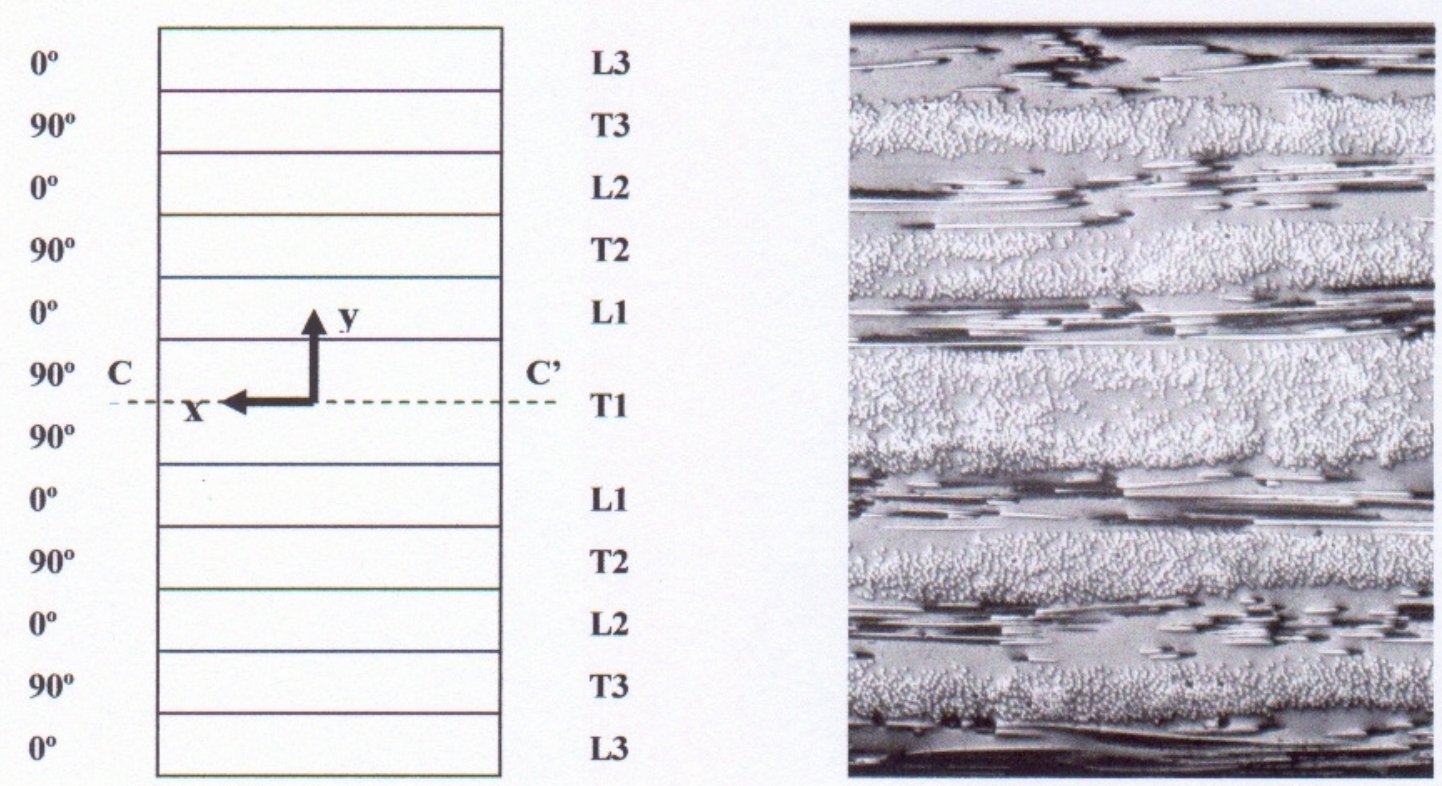

Figure 7 The nomenclature used to describe damage due to thermal shock on a $(0 / 90)_{3 \mathrm{~s}}$ laminate

For this Nicalon/CAS laminate $\Delta \mathrm{T}_{\mathrm{c}}=350^{\circ} \mathrm{C}$. The form of thermal shock damage observed was matrix cracking, which can be further divided into PMCs and HMCs. The fibres remained unaffected at all shocks.

HMCs were the first form of damage observed after quenching through $\Delta \mathrm{T}_{\mathrm{c}}=350^{\circ} \mathrm{C}$. They were located exclusively in $90^{\circ}$ plies. Depending on the specimen under observation, these cracks emanated either from flaws, such as pores, and were contained inside the ply, or originated from the edges of the ply and ran towards its centre. They were continuously deflected at successive fibre-matrix interfaces.

PMCs were detected on the surfaces of thermally-shocked specimens, exclusively in $0^{\circ}$ plies, after quenching through $\Delta \mathrm{T}=400^{\circ} \mathrm{C}$. These cracks ran perpendicular to the horizontal (i.e. to the longitudinal fibres of the $0^{\circ}$ plies), leaving the fibres on their path unaffected, and arrested either at a fibre-matrix interface inside the ply or at the interfaces between $0^{\circ}$ and $90^{\circ}$ plies. 
The evolution of both types of damage with increasing applied $\Delta \mathrm{T}$ can be seen in the sequence of reflected light microscopy images of Fig. 8.

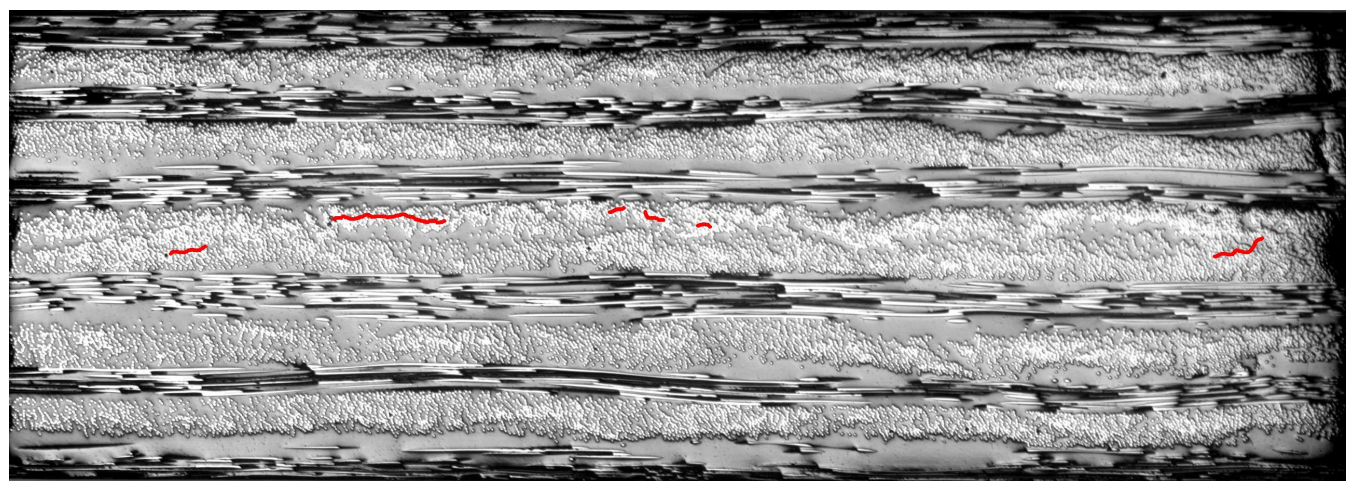

(a)

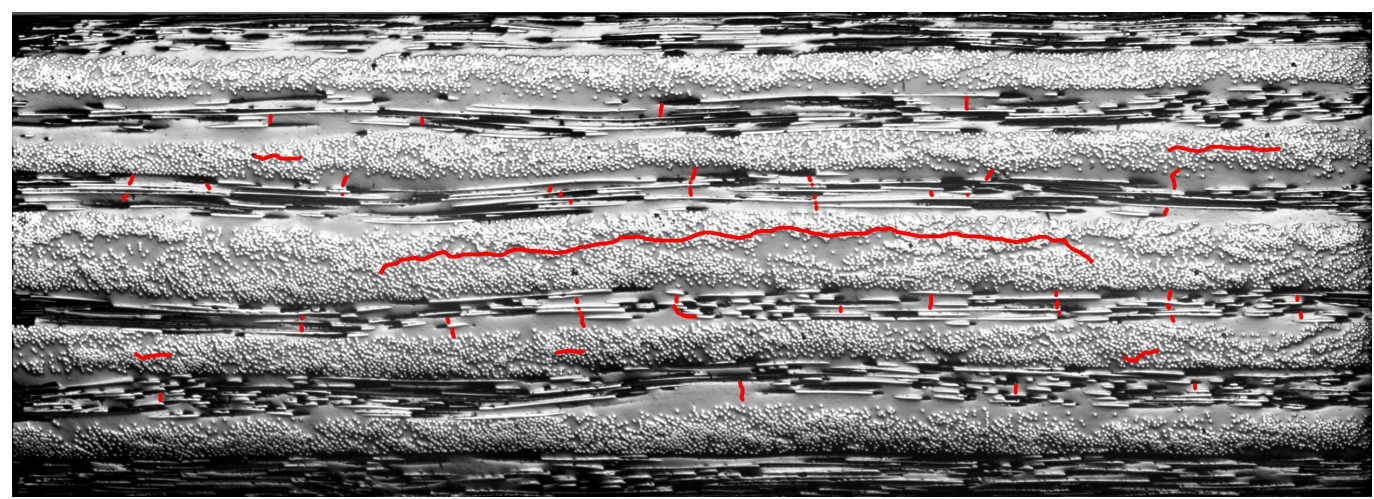

(b)

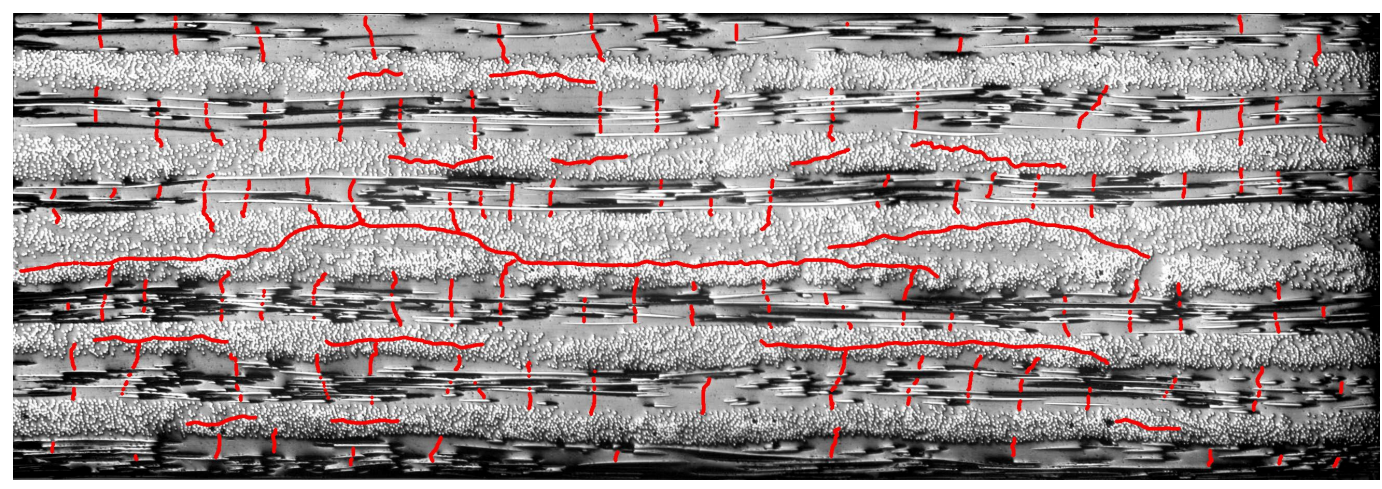

(c)

Figure 8 Photomicrographs of quenched surfaces of $(0 / 90)_{3 \mathrm{~s}}$ Nicalon/CAS with crack pattern superimposed for $\Delta \mathrm{T}$ of (a) $350^{\circ} \mathrm{C}$, (b) $500^{\circ} \mathrm{C}$ and (c) $700^{\circ} \mathrm{C}$.

At $\Delta \mathrm{T}=350-400^{\circ} \mathrm{C}$ only random $\mathrm{HMCs}$ could be generally seen in the thick, central transverse ply (T1). However, a much longer crack was also evident at some specimens quenched at this temperature differential. These cracks were limited to the surface of the material. 
At $\triangle \mathrm{T}=400^{\circ} \mathrm{C} \mathrm{PMCs}$ appeared at the $0^{\circ}$ plies (L1) adjacent to $\mathrm{T} 1$ while longer, random $\mathrm{HMCs}$ could again be seen in T1. Damage, in the form of PMCs and HMCs, appeared in the $0^{\circ}$ plies designated as $\mathrm{L} 2$ and the $90^{\circ}$ plies designated as $\mathrm{T} 2$, respectively, at $\Delta \mathrm{T}=450^{\circ} \mathrm{C}$. At this temperature differential, a long HMC propagated along the central T1 ply while in the T2 plies only individual HMCs appeared.

Similar patterns were observed at $\Delta \mathrm{T}=500^{\circ} \mathrm{C}$. However, almost all PMCs spanned the thickness of the L1, L2 plies while some started to extend into the adjacent $90^{\circ}$ plies. In addition, some HMCs in the T2 plies connected to form longer cracks.

At $\Delta \mathrm{T}=600^{\circ} \mathrm{C}$ all plies of this system sustained some form of thermal shock damage; $\mathrm{T} 1$ contained a long, deep HMC, T2 exhibited shorter and shallower HMCs, while individual, random HMCs could be seen in T3. In addition, all longitudinal plies (L1, L2, L3) contained PMCs, the number of which decreased on going from the centreline (C-C') towards the top or bottom edges of the surface.

The application of even higher $\Delta \mathrm{Ts}\left(=700-800^{\circ} \mathrm{C}\right)$ lead to an increase in the number of PMCs in the longitudinal plies, although it again looked as if the plies closer to the centreline had higher densities of these cracks than those further away. In addition, some PMCs (especially in L1) could be seen to extend into the adjacent transverse plies (T1 and T2). HMCs followed a more random pattern. There was always a long, deep crack that travelled along almost the full length of the ply in either T1 or T2. The rest of these plies contained shorter and shallower cracks while the cracks located in T3, although continuously increasing in number and length, failed to connect into longer HMCs even at the highest $\Delta \mathrm{T}$.

In general, the application of higher $\Delta \mathrm{Ts}$ did not affect the morphology of PMCs. In contrast, HMCs located at transverse plies at or close to the centreline of the face became deeper and their opening, as well as their length, increased significantly at the highest temperature differentials investigated (Fig. 9). 


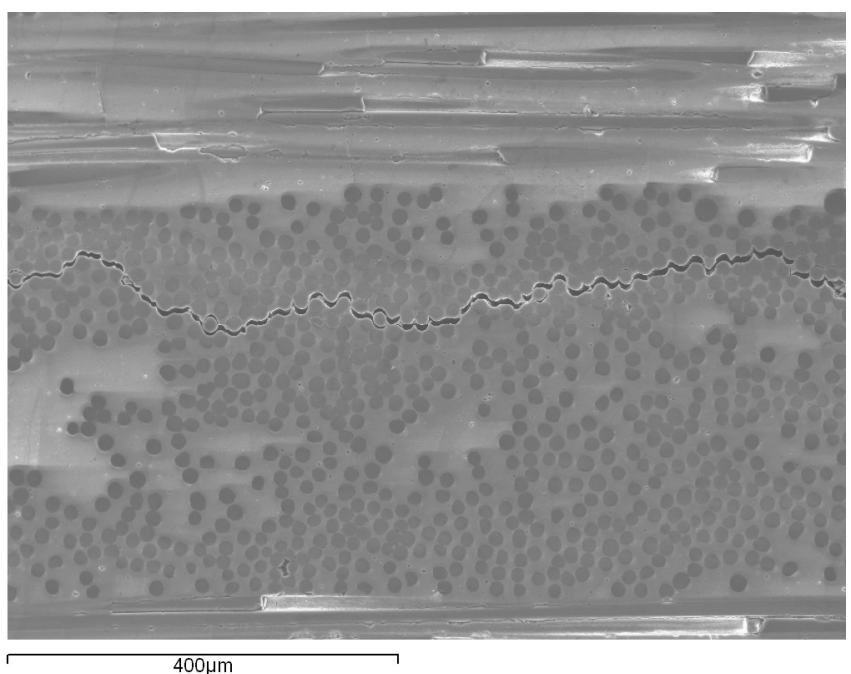

Figure 9 SEM image showing deep HMC in the central transverse ply at a high temperature differential.

PMCs were evenly distributed between the longitudinal plies of the same designation (i.e. L1, L2 or L3). This was not exactly the case for HMCs as these were distributed in a more random fashion, especially at the higher temperature differentials, between the pairs of transverse plies (i.e. T1, T2 or T3) depending on the specimen under investigation

The increase in PMC density with increasing shock severity for each set of longitudinal plies (L1, L2, L3) is shown in the graph of Fig. 10a. It is evident that crack density is always higher for the plies located towards the centre of the sample surface, i.e. $\mathrm{CD}_{\mathrm{L} 1}>\mathrm{CD}_{\mathrm{L} 2}>\mathrm{CD}_{\mathrm{L} 3}$ at each $\Delta \mathrm{T}$ investigated (CD: Crack Density). The rates of increase of cracking in each set of plies are comparable.

Fig. 10b shows the change in HMC density with increasing temperature differential. A significant increase in cracking can be observed, especially at the higher thermal shocks. In addition, the scatter in experimental data is larger at the higher temperature differentials, which reflects the randomness in the appearance and point of origin of long cracks in T1 and/or T2.

Comparison between PMCs and HMCs (Fig. 10b) reveals that the rate of increase in density of PMCs is much higher than that of HMCs and, at high temperature differentials, PMCs are the major contribution to the total crack density. However, this graph fails to capture the significant differences in morphology between the two types of matrix cracking at $\Delta \mathrm{T} \geq 600^{\circ} \mathrm{C}$. 


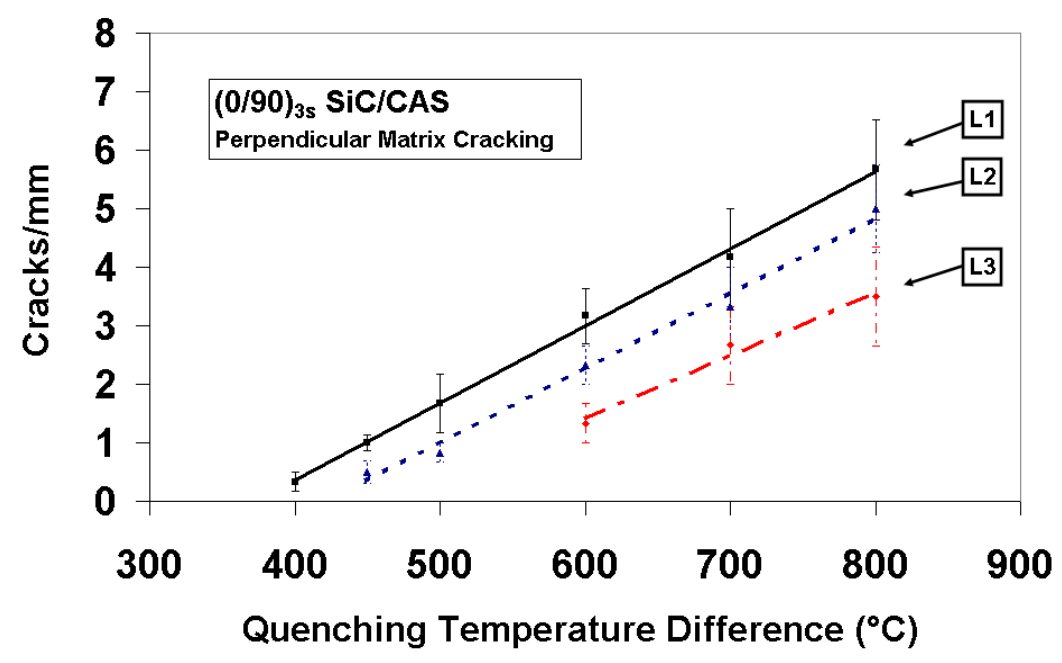

(a)

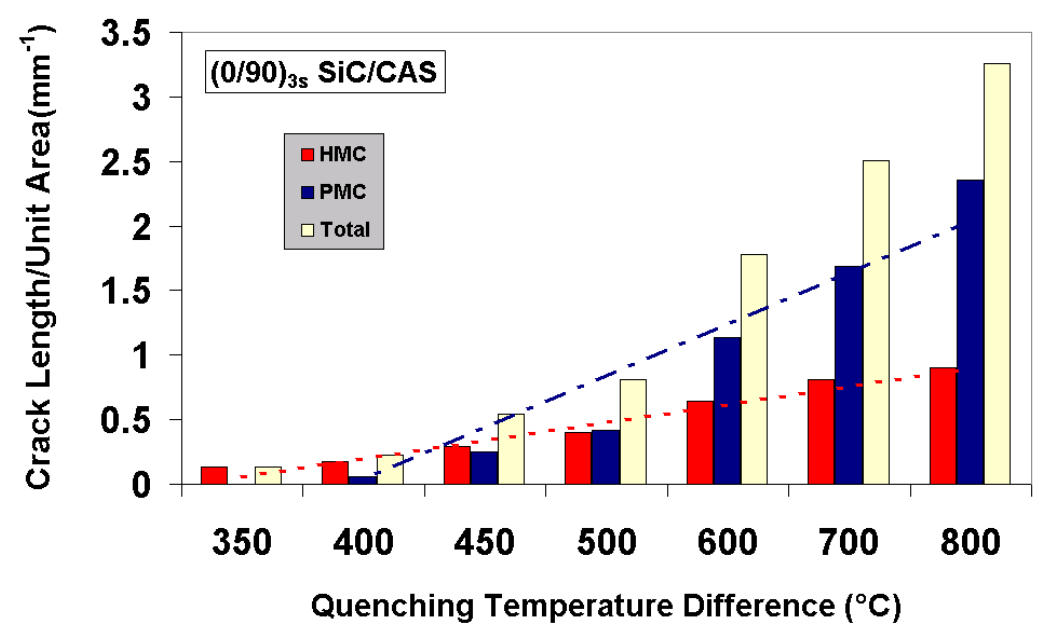

(b)

Figure 10 (a) Crack density as a function of $\triangle \mathrm{T}$ for PMCs for each set of longitudinal plies of $(0 / 90)_{3 \mathrm{~s}}$ Nicalon/CAS laminate. Note that $\mathrm{CD}_{\mathrm{L} 1}>\mathrm{CD}_{\mathrm{L} 2}>\mathrm{CD}_{\mathrm{L} 3}$ at all $\Delta \mathrm{Ts}$ and (b) Crack densities of PMCs and HMCs and total crack density at each $\Delta \mathrm{T}$.

\subsubsection{The $\left(90^{\circ} / 0^{\circ}\right)_{3 \mathrm{~s}}$ Laminate}

The description of this laminate is similar to that of the $\left(0^{\circ} / 90^{\circ}\right)_{3 \mathrm{~s}}$ laminate except that the central ply is now L1, not T1, and the next plies are T1, not L1, and so on, ending with T3 outer plies.

Initial damage due to thermal shock was detected on the surfaces of this laminate after quenching through temperature differentials higher than $400^{\circ} \mathrm{C}$, i.e. $\Delta \mathrm{T}_{\mathrm{c}}=400^{\circ} \mathrm{C}$ for this laminate. In general, thermal shock damage on this laminate for the range of temperature differentials investigated was in the form of PMCs and HMCs. 
HMCs as a result of thermal shock were first visible on this laminate after quenching through $\Delta \mathrm{T}_{\mathrm{c}}=400^{\circ} \mathrm{C}$. They could be seen to propagate along the surface of the $90^{\circ}$ plies. Although they generally ran horizontally, successive fibre-matrix interfaces deflected them continuously. PMCs were also detected after quenching through the critical temperature differential, i.e. at $\Delta \mathrm{T}_{\mathrm{c}}=400^{\circ} \mathrm{C}$. They appeared only in $0^{\circ}$ plies. Their advance was at right angles to the longitudinal fibres, which remained unaffected since PMCs were deflected at fibre-matrix interfaces.

The evolution of both types of damage with increasing applied $(\Delta T)$ can be seen in the sequence of RLM images of Fig. 11.

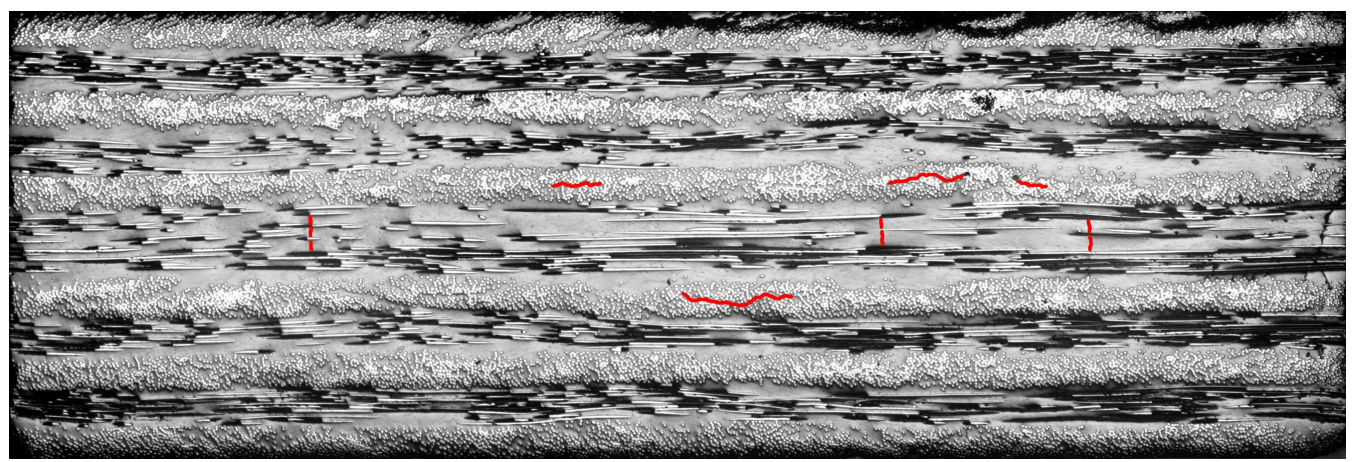

(a)

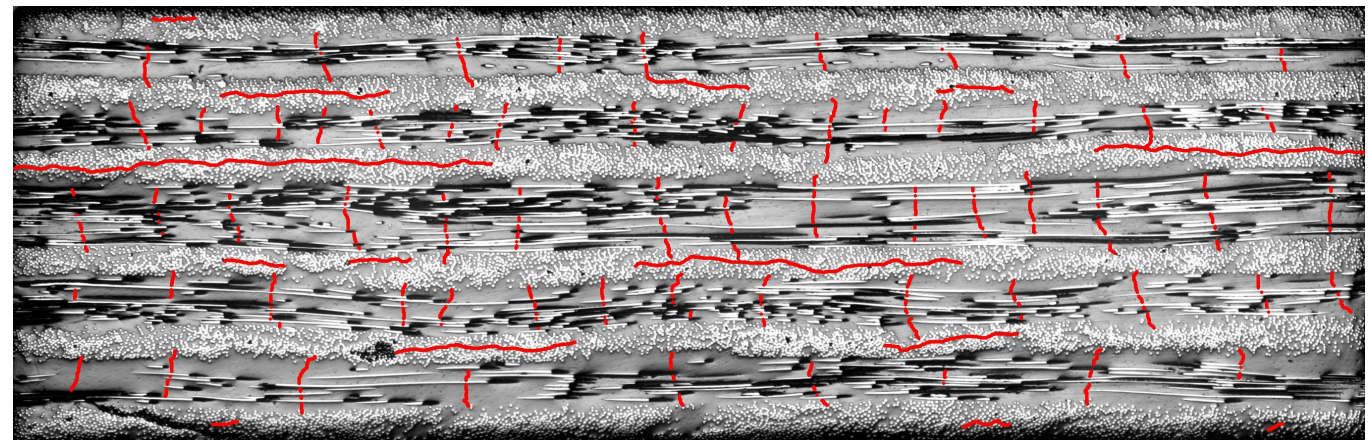

(b)

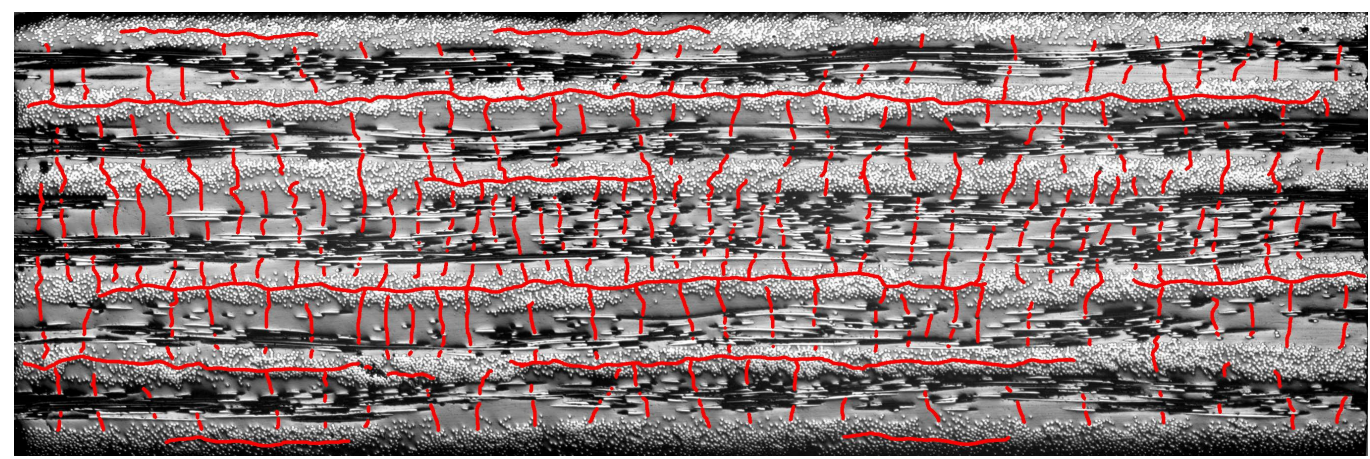

(c)

Figure 11 Photomicrographs of quenched surfaces of $(90 / 0)_{3 \mathrm{~s}}$ Nicalon/CAS with crack pattern superimposed for $\Delta \mathrm{T}$ of (a) $450^{\circ} \mathrm{C}$, (b) $600^{\circ} \mathrm{C}$ and (c) $800^{\circ} \mathrm{C}$. 
At the onset of fracture $\left(\Delta \mathrm{T}_{\mathrm{c}}=400^{\circ} \mathrm{C}\right)$, damage was only visible in the central plies of this laminate. PMCs in L1 did not bridge the ply thickness while HMCs in T1 were associated mainly with open pores.

The application of temperature differentials up to $\Delta \mathrm{T}=500^{\circ} \mathrm{C}$ did not change the morphology of either type of matrix cracks: they remained shallow surface features. However, PMCs were also visible in L2 and L3 and the presence of $\mathrm{HMCs}$ extended to $\mathrm{T} 2$. At $\Delta \mathrm{T}=500^{\circ} \mathrm{C}, \mathrm{HMCs}$ of significant length could be seen originating either inside $\mathrm{T} 1$ and $\mathrm{T} 2$ or from the ply edges running towards the centre of the specimen.

The length and depth of HMCs in $\mathrm{T} 1$ became much larger at $\Delta \mathrm{T}=600^{\circ} \mathrm{C}$. At this temperature differential, damage was detected in every ply of the laminate. PMCs could be seen bridging the thicknesses of their respective plies and some extended into adjacent transverse plies. The population of these cracks seemed higher the closer the longitudinal ply was located to the centreline $\left(\mathrm{C}^{-} \mathrm{C}^{\prime}\right)$ of the polished surface. The same was true for the traverse plies.

Application of even higher temperature differentials resulted in long, deep HMCs in T1 and T2 (with depth always being higher in T1), longer HMCs in T3, and multiplication of PMCs in all longitudinal plies. However, the depth of PMCs even in L1 did not increase. In addition, only short HMCs were visible in the outer T3 plies. PMCs were distributed uniformly between longitudinal plies with the same designation. By contrast, HMCs accumulated in the pairs of transverse plies in a more irregular fashion. The differences in depth between HMCs in T1, T2, and T3 can be clearly seen in the SEM images of Fig. 12.

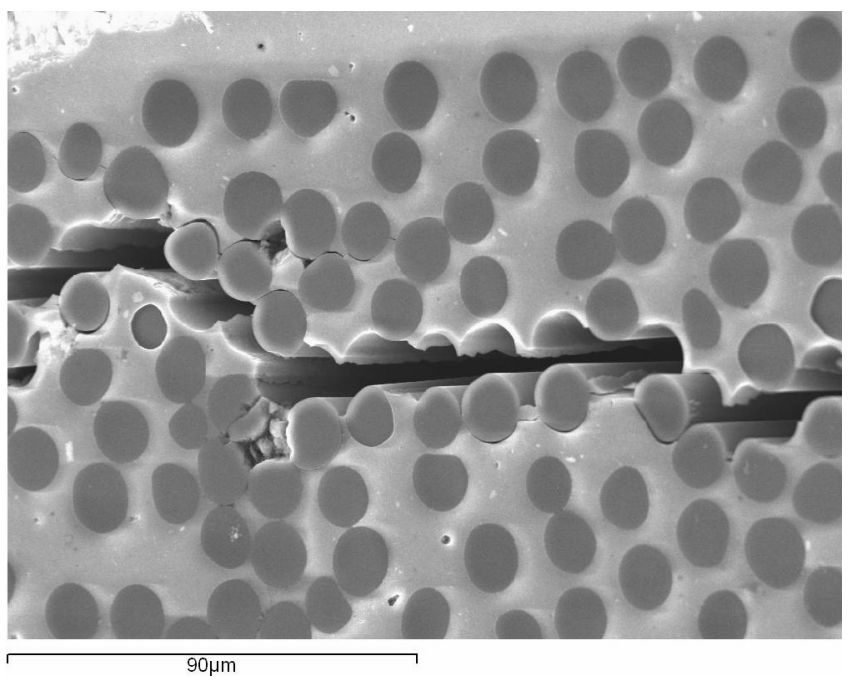



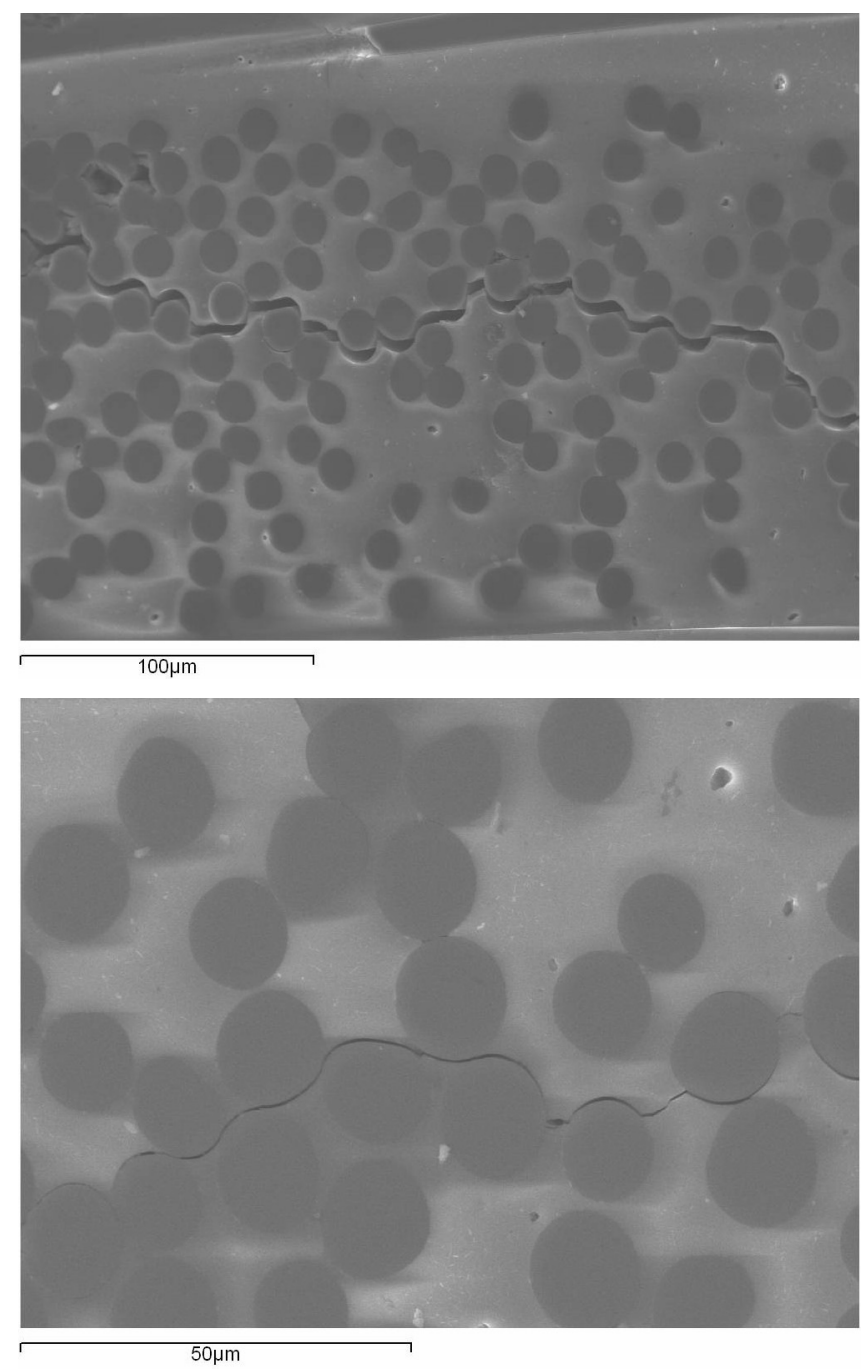

Figure 12 SEM images of HMC in (a) T1, (b) T2, and (c) T3 at $\Delta \mathrm{T}=800^{\circ} \mathrm{C}$. The differences in depth can be clearly observed.

The accumulation of damage in the $0^{\circ}$ plies of this laminate at increasing thermal shocks can be seen in the graph of Fig. 13a. Significant increases in crack density are evident and at each temperature differential $\mathrm{CD}_{\mathrm{L} 1}>\mathrm{CD}_{\mathrm{L} 2}>\mathrm{CD}_{\mathrm{L} 3}$. The rate of increase in cracking for $\mathrm{L} 1$ looks to be higher than the rates of increase for L2 and L3. However, the scatter of the experimental results does not allow safe conclusions to be reached.

The accumulation of damage in the transverse plies of this laminate is shown in Fig. 14b. The density of HMCs increases continuously with the application of higher temperature differentials at a high rate. Note that only the total crack density is plotted at each $\Delta \mathrm{T}$. Generally, it can be assumed that $\mathrm{CD}_{\mathrm{T} 1}>\mathrm{CD}_{\mathrm{T} 2}>\mathrm{CD}_{\mathrm{T} 3}$ at each temperature differential. However, whether $\mathrm{CD}_{\mathrm{T} 1}$ or $\mathrm{CD}_{\mathrm{T} 2}$ was higher was mostly a random result that depended on the point of origin of the respective HMCs. In general, HMCs emanating from ply edges ran for 
longer lengths. From the comparison of crack densities of each type of damage at each $\Delta \mathrm{T}$ it can be seen that PMCs accumulate at a much higher rate than HMCs.

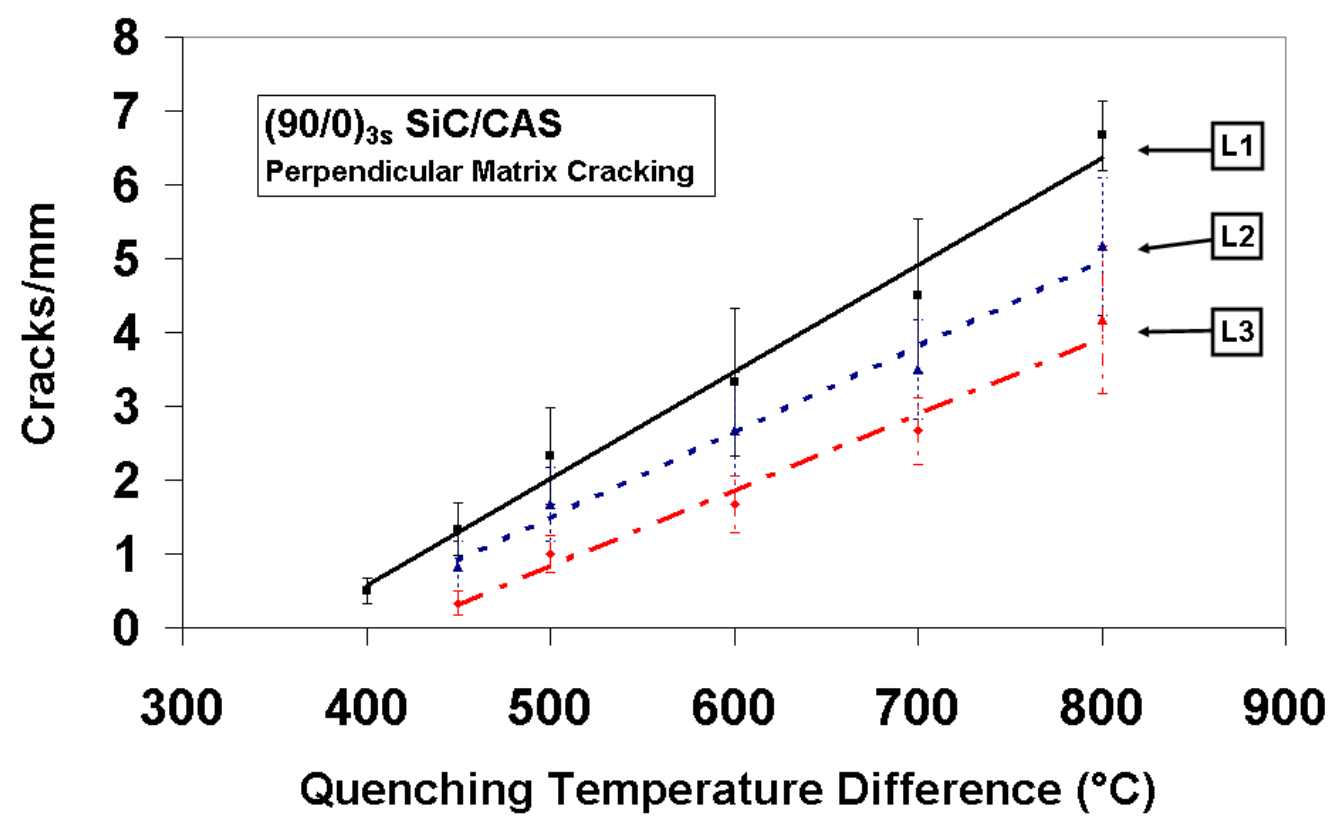

(a)

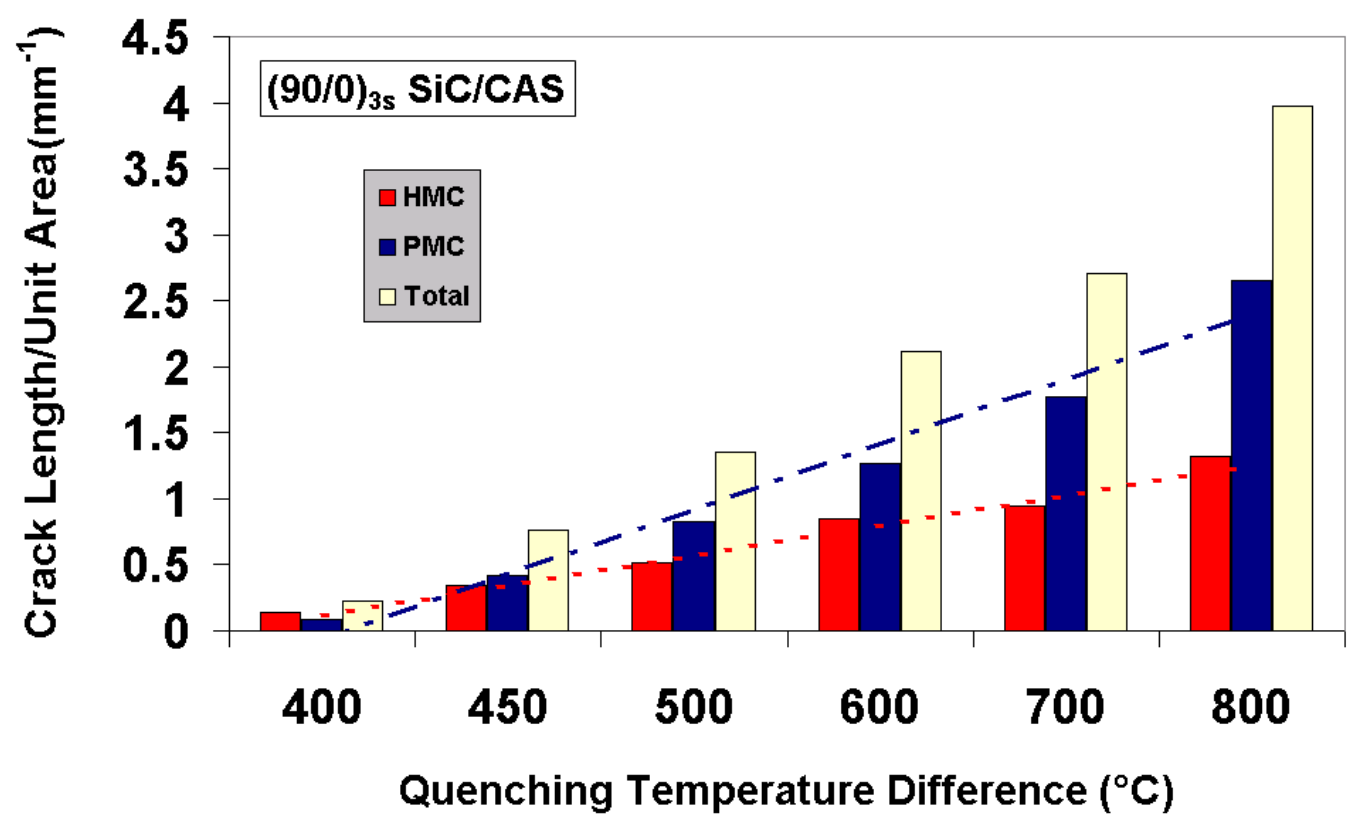

(b)

Figure 13 (a) Crack density as a function of $\Delta \mathrm{T}$ for PMCs for each set of longitudinal plies of $(90 / 0)_{3 \mathrm{~s}}$ Nicalon/CAS laminate. Note that $\mathrm{CD}_{\mathrm{L} 1}>\mathrm{CD}_{\mathrm{L} 2}>\mathrm{CD}_{\mathrm{L} 3}$ at all $\Delta \mathrm{Ts}$ and (b) Crack densities of PMCs and HMCs and total crack density at each $\Delta \mathrm{T}$. Relevant trends for each damage mode are also shown. 


\subsubsection{Summary of Observations of Multi-Layer Cross-Ply Nicalon/CAS}

\section{Laminates}

Damage modes due to thermal shock and their accumulation with increasing shock severity in specimens of two laminate configurations of multi-layer cross-ply Nicalon/CAS CMCs were described in detail in this section. Matrix cracks of various orientations were identified as the main mode of damage. In longitudinal plies these cracks propagated at right angles to the surface fibre length whereas in transverse plies they ran along the length of the ply. As these matrix cracks were deflected upon encountering fibre-matrix interfaces, no fibre breaks could be detected at any ply even at the highest thermal shocks.

The critical quenching temperature difference was found to be higher for the $\left(90^{\circ} / 0^{\circ}\right)_{3 \mathrm{~s}}$ laminate. Damage in both laminates originated at the central, thick plies and, in the case of the $\left(90^{\circ} / 0^{\circ}\right)_{3 \mathrm{~s}}$ system, at those adjacent to them. With the application of higher differentials, damage extended to the outer plies until, at intermediate shocks $\left(\Delta \mathrm{T}=600^{\circ} \mathrm{C}\right)$, the surfaces of all plies were fractured. At even higher quenching temperature differences, damage became more extensive, especially the PMCs in longitudinal plies. However, HMCs in transverse plies were observed, apart from increasing in length, to penetrate deeper and deeper into the matrix. The extent of thermal shock damage exhibited a gradient across the material surface: higher crack densities and deeper HMCs were located at or close to the centreline. On moving towards the outer plies the extent of the damage reduced significantly.

In terms of the number of cracks and their measured length as a function of the surface area, damage in the form of PMCs was found to be much more extensive compared with that in the form of HMCs, especially at severe thermal shocks. However, whereas PMCs propagated only at the surface of the laminate, HMCs could be seen to extend deeply into the matrix for $\Delta \mathrm{T} \geq 600^{\circ} \mathrm{C}$ as was evident from their increased opening. Unfortunately, the depth they penetrated could not be determined with any particular accuracy experimentally. However, judging from the openings of the crack surfaces at the surface, the extent of their propagation on the surface (from edge to edge for some specimens at severe shocks), and the fact that in these configurations they cannot meet any ply interface in the depth direction, it can be concluded that their advance must be significant and possibly compromises the structural integrity of the laminate. 


\section{Discussion}

A number of general observations can be made regarding the thermal shock behaviour of the laminates analysed in the previous sections. The main mode of damage after thermal shock treatment in all laminates, irrespective of configuration, is the formation of cracks in the matrix. These cracks were deflected at fibre-matrix interfaces and, thus, did not result in any damage to the fibres, as is expected for optimally-designed fibre-reinforced CMCs. This is in accordance with reports of thermal shock damage in similar materials published in the literature (e.g. [3-7]). However, matrix cracks in different plies advanced towards different directions: at right angles to the exposed fibre length in longitudinal plies and along the length of the ply surface in transverse plies. This seems to be a general feature of this class of CMCs. More specifically, Kagawa et al. [3], Blissett et al. [4], and Boccaccini et al. [5, 6] reported PMCs in longitudinal faces of UD Nicalon/Pyrex, Nicalon/CAS, and Nicalon/DURAN respectively. In addition, Blissett et al. [14] presented evidence of PMCs in the longitudinal plies of $\left(0^{\circ}{ }_{2} / 90^{\circ}{ }_{4}\right)_{\mathrm{s}}$ and $\left(0^{\circ} / 90^{\circ}\right)_{3 \mathrm{~s}}$ laminates. In contrast, cracks similar to the HMCs described in this paper have been reported for the end faces of UD Nicalon/CAS [4] and Nicalon/LAS II [10], as well as for the transverse plies of $\left(0^{\circ}{ }_{2} / 90^{\circ}{ }_{4}\right)_{\mathrm{s}}$ and $\left(0^{\circ} / 90^{\circ}\right)_{3 \mathrm{~s}}$ laminates [14]. This provides evidence for the biaxiality of the surface stresses develop as a result of thermal shock, as under uniaxial tensile testing only PMCs (as defined here) can be seen on the surfaces of UD or cross-ply CMCs (e.g. [16]).

Fibre failures, such as those reported by Blissett et al. [4], were not detected in this investigation. As these authors associated the occurrence of such damage patterns with material degradation after high-temperature exposure, it can be concluded that their absence in this study resulted from the short times the material samples were held at high temperature, which did not allow the formation of any oxidation products on the material surfaces.

The lower thickness of the simple cross-ply laminates had a major effect on their thermal shock resistance as these laminates exhibited critical temperature differentials $\sim 100^{\circ} \mathrm{C}$ higher than those of their multi-layer counterparts. This is a well-documented aspect of the thermal shock behaviour of ceramic materials. It has been shown that a critical dimension exists above 
which the $\Delta \mathrm{T}_{\mathrm{c}}$ becomes independent of material dimensions. Samples with at least one dimension lower than this critical value exhibit much higher resistance to thermal shock [1].

The lower thickness of the simple cross-ply laminates seems also to affect the energy available for crack propagation. All matrix cracks in these systems, irrespective of them being PMCs or HMCs, are confined to the surfaces of these materials even when the material was subjected to the highest temperature differential. By contrast, HMCs in the thicker multi-layer laminates became much deeper as the applied shock increased in severity.

The difference with which each type of ply accommodates the energy available for crack propagation must be highlighted. The application of more severe shocks in longitudinal $\left(0^{\circ}\right)$ plies results in the rapid multiplication of surface cracks, which also seem to appear at regular intervals along the ply length. This is similar to the situation under tensile testing (e.g. Pryce and Smith [16]), and implies that stress transfer may take place during thermal shock between fibre/matrix and between different plies. This stress transfer mechanism results in the energy available for cracking in $0^{\circ}$ plies to be consumed mainly in multiplying the number of cracks; in contrast, in $90^{\circ}$ plies, as no transfer takes place and the energy available results in the extension (in length and depth) of a small number of cracks that appear at preferential sites. These cracks do not increase in number but become deeper and deeper at higher temperature differentials, something that would affect the integrity of the material. From this aspect, transverse plies behave in a similar way to monolithic or particulate-reinforced ceramic materials under thermal shock loading. In contrast, longitudinal plies show true 'composite', and thus superior, behaviour under thermal shock conditions.

Finally, this study revealed an important aspect of the behaviour of cross-ply Nicalon/CAS under conditions of thermal shock: cracking always originated at the central plies and, in particular, at or near the centreline of the face. In addition, crack densities in the central plies were higher at all $\Delta$ Ts compared with those of plies located towards the top and bottom edges. Blissett et al. [4] also reported that the major, deep crack due to thermal shock always ran along the centreline of the quenched end-face of a UD Nicalon/CAS. This shows that the highest stress at each $\Delta \mathrm{T}$ occurs always at the centreline and gradually reduces as the top and bottom edges are approached. This was true especially for PMCs in longitudinal plies. HMCs followed a more random pattern but plies towards the centreline always had longer and deeper cracks. 


\section{Concluding Remarks}

Damage due to thermal shock in a range of simple and multi-layer cross-ply Nicalon/CAS CMCs was characterised in this paper.

Cracking always originated in the central plies and consisted of matrix cracks of various directions depending on the orientation of each ply. Application of shocks of increasing severity resulted in damage being extended to the remaining plies, although crack density was always higher the closer a ply was located to the centreline of the face under investigation. At the same time, cracks in $0^{\circ}$ plies multiplied in number but remained surface features while cracks in $90^{\circ}$ plies increased moderately in length but significantly in depth.

The effect material dimensions have on the onset of thermal shock cracking and the extent of damage at increasing shock severity was also highlighted. Thinner laminates exhibit higher resistance to thermal shock and lower accumulation of thermal shock damage.

\section{Acknowledgements}

The authors would like to thank Rolls-Royce plc. for the provision of experimental materials. CK acknowledges financial support from the Engineering and Physical Sciences Research Council (UK) and the 'Alexander S. Onassis' Public Benefit Foundation. The help of Mr. Mike Parker and Mr. Nick Ludford with specimen preparation is gratefully acknowledged.

\section{References}

1. H. Wang and R. N. Singh, Int. Mat. Rev. 39 (1994) 228

2. C. Kastritseas, P. A. Smith and J. A. Yeomans, in "Ceramic Matrix Composites: Microstructure-Property Relationship" (Woodhead Publishing Ltd., ISBN 185573 942 9, 2005)

3. Y. Kagawa, N. Kurosawa and T. Kishi, J. Mater. Sci. 28 (1993) 735

4. M. J. Blissett, P. A. Smith and J. A. Yeomans, J. Mater. Sci. 32 (1997) 317 
5. A. R. Boccaccini, D. H. Pearce, J. Janczak, W. Beier and C. B. Ponton, Mat. Sci. Tech. 13 (1997) 852

6. A. R. Boccaccini, J. Janczak-Rusch, D. H. Pearce and H. Kern, Comp. Sci. Tech. 59 (1999) 105

7. A. R. Boccaccini, Scripta Mater. 8 (1998) 1211

8. A. R. Boccaccini, H. Kern H and I. Dlouhy I, Mater. Sci. Eng. A308 (1/2) (2001) 111

9. C. Kastritseas, P. A. Smith and J. A. Yeomans, Comp. Sci. Tech. accepted for publication

10. S. Graham, D. L. McDowell, E. Lara-Curzio, R. B. Dinwiddie, H. Wang and W. Porter, J. Comp. Mater. 37(1) (2003) 73

11. H. Wang, R. N. Singh and R. A. Lowden R A, J. Am. Ceram. Soc. 79(7) (1996) 1783

12. J. E. Webb, R. N. Singh and R. A. Lowden, J. Am. Ceram. Soc. 79(11) (1996) 2857

13. Y. Kagawa Y, Comp. Sci. Tech. 57 (1997) 607

14. M. J. Blissett, P. A. Smith and J. A. Yeomans, J. Mater. Sci. 33 (1998) 4181

15. H. Wang, R. N. Singh and R. A. Lowden R A, J Mater. Sci. 32 (1997) 3305

16. A. W. Pryce and P. A. Smith, J. Mater. Sci. 27 (1992) 2695 